\title{
Detection of Virulence Markers in Uropathogenic Escherichia coli, their Serotypes and Antibiotic Sensitivity Patterns
}

\author{
Tarulata Saikia $^{1 *}$, Jayanta Kr. Das ${ }^{2}$, Dipa Barkataky ${ }^{1}$ and N. K. Hazarika ${ }^{1}$ \\ ${ }^{1}$ Department of Microbiology, Gauhati Medical College and Hospital, \\ Guwahati-781032, Assam, India \\ ${ }^{2}$ Department of Pathology, Silchar Medical College and Hospital, Silchar- 788014, Assam, India \\ *Corresponding author
}

\section{Keywords}

Uropathogenic

Escherichia coli,

UPEC,

Virulence

markers,

Serotype

\section{Article Info}

Accepted:

24 March 2016

Available Online:

10 April 2016

\section{A B S T R A C T}

Escherichia coli remains the predominant uropathogen (70-90\%) isolated from acute community acquired uncomplicated infections. E. coli present in the gastrointestinal tract, as commensals provide the pool for initiation of urinary tract infection. Subsets of fecal $E$. coli with specific virulence factors that can colonize the periurethral area, enter the urinary tract and cause disease are known as uropathogenic E. coli (UPEC). The most important amongst the virulence markers, are adhesins like type 1 fimbriae, $P$ fimbriae. Other factors associated with UPEC include production of Hemolysin and cell surface hydrophobicity. 210 isolates of E. coli from urinary tract infection were screened for virulence markers Hemolysin, Surface Hydrophobicity and Mannose resistant \& Mannose sensitive Haemagglutination. Monovalent E. coli antisera belonging to serogroups 01, 06, 08, 015, 018, 020, 025 (Denka Seikien, Tokyo, Japan) were used for serotyping. All the isolates were also studied for an antibiotic susceptibility pattern using Kirby Bauer disk diffusion method. Among 210 isolates, $35.71 \%$ were Hemolytic, 29.04\% were Hydrophobic, 28\% showed Mannose-resistant Haemagglutination and $11 \%$ showed Mannose-sensitive Haemagglutination. Multiple (all) virulence factors tested were observed in $29(24.78 \%)$ of isolates. It was observed that $26.8 \%(15 / 56)$ isolates belonged to the serogroup O6, followed by O8 (23.2\%). Isolated $E$. coli was found to be most sensitive to Nitrofurantoin $(85.71 \%)$, followed by Gentamicin (78.09\%) and least sensitive to Ampicillin. The present study showed the expression of virulence factors and multiple drug resistance in $E$. coli isolated from urinary tract infection.

\section{Introduction}

Escherichia coli remains the predominant uropathogen (70-90\%) in cases of acute community acquired uncomplicated infections in anatomically normal, unobstructed urinary tracts and is also responsible for $85 \%$ of asymptomatic bacteriuria and for more than $60 \%$ of recurrent cystitis (Foxman B., 2003).

Commensal E. coli present in the 
gastrointestinal tract provide the pool for initiation of UTI (Raksha R et al., 2003). Some strains of $E$. coli deviates from their commensal status as intestinal flora of mammals and take on a pathogenic course with development of capability to cause disease both within and outside the gut. Subsets of fecal E. coli with specific virulence factors that can colonize the periurethral area, enter urinary tract and cause disease are known as uropathogenic $E$. coli (UPEC) (Kaper JB et al., 2004). Virulence is defined as the ability of an organism to cause disease in a particular host. In $E$. coli virulence results from the cumulative impact of one or several special properties, or Virulence factors (VFs), which serve to distinguish potential pathogen from harmless intestinal strains (Johnson JR., 1991). It has been traditionally described that certain serotypes of E.coli were consistently associated with uropathogenicity and these isolates express chromosomally encoded virulence markers.

The virulence factors of E. coli is broadly grouped into two categories, surface virulence factors and exported virulence factors (Agarwal J et al., 2012). The most important amongst the virulence markers, are the adhesins that help them to adhere to uroepithelium (Eden CS et al., 1976; Sandberg $\mathrm{T}$ et al., 1988). The type 1 fimbriae are widely prevalent and they may be involved in colonization of lower urinary tract (Nataro JP, Mobley HL., 2004; Wullt B., 2003). Type 1 fimbriae is present in $>90 \%$ of commensal and pathogenic E. coli. It helps the bacterium to adhere mucosal epithelium and tissue matrix, and biofilm formation (Agarwal $\mathrm{J}$ et al., 2012). Attachment of $\mathrm{P}$ fimbriae is also associated with increased host inflammatory response (Wullt B., 2003). It is present in 40-60\% of UPEC isolates (Agarwal J et al., 2012).
Other factors associated with uropathogenic $E$. coli include production of haemolysin. Haemolysin provides E.coli with possible selective advantage by releasing iron from lysed erythrocytes and enhances pathogenicity by destroying phagocytic and epithelial cells (Nataro JP, Mobley HL., 2004; Wullt B., 2003). Cell surface hydrophobicity of the bacterial cell surface promotes their adherence to various surfaces like mucosal epithelial cells. It is responsible for recurrent UTI (Johnson JR., 1991).

The knowledge of drug resistance pattern in a geographical area and the formulation of appropriate hospital antibiotic policy will go a long way in control of infections (Sharma S et al., 2007).

Keeping these things in mind the present study was undertaken to know the prevalence of various virulence markers viz Hemolysin, Cell surface hydrophobicity and Haemagglutination present in UPEC along with their antibiotic susceptibility pattern.

\section{Materials and Methods}

The study was conducted in the Department of Microbiology, Gauhati Medical College and Hospital, Guwahati from July 2012 to June 2013. A total of 210 E.coli isolated from cases of UTI were processed during the study period. E. coli was identified as described by Bailey and Scott (Forbes BA et al., 2007).

\section{Haemolysin}

The isolates to be tested were subcultured onto 5\% sheep blood agar and incubated overnight at $37^{\circ} \mathrm{C}$. Haemolysin was detected by determining a clear haemolytic zone (Figure: 3) ( $\beta$-haemolysis) around each colony (Raksha R et al., 2003). 


\section{Cell Surface Hydrophobicity}

Different molar concentrations of Ammonium-sulphate including $1 \mathrm{M}, 1.4 \mathrm{M}$ and $2 \mathrm{M}$ were prepared. Forty microliter of $0.2 \mathrm{M}$ PBS (pH 6.8) was taken in the first column of the multiple concavity slide. Forty microliter of $1 \mathrm{M}, 1.4 \mathrm{M}$ and $2 \mathrm{M}$ concentration of ammonium sulphate were taken in each well of other columns of the multiple concavity slide. Forty microliter of E. coli suspension $\left(5 \times 10^{9} \mathrm{cfu} / \mathrm{ml}\right)$ was added to each of these wells. The clumps formed in different molar concentration of ammonium sulphate were observed with naked eye and under Leights Wetzler inverted microscope binocular (0.32) at 20x magnification. The strains were considered hydrophobic if they aggregated in concentrations of $1.4 \mathrm{M}$ (Raksha R et al., 2003).

\section{Haemagglutination}

Colonies of E. coli was inoculated into $1 \%$ Nutrient broth and incubated at $37^{\circ} \mathrm{C}$ for full fimbriation. $1-2 \mathrm{ml}$ of Human $\mathrm{O}$ positive blood was collected. The RBCs were washed 3 times with Normal saline. Then $3 \%$ suspension of RBCs were prepared in Normal saline. They can be stored for a week at $3-5^{\circ} \mathrm{C}$. On multiple concavity slide one drop of broth culture was taken and to it one drop of the RBC suspension was added. The slide was rocked to and fro at room temperature for 5 minutes. Presence of clumping was taken as positive for haemagglutination (Figure: 4). In a parallel set of test one drop of $2 \%$ w/v D-mannose was added to the red cells and a drop of broth culture. Slide was rocked to and fro for 5 minutes.

Mannose-sensitive haemagglutination was detected by the absence of haemagglutination in presence of $2 \% \mathrm{w} / \mathrm{v} \mathrm{D}$ mannose in the parallel set of test.
Mannose-resistant haemagglutination was detected by the presence of haemagglutination when 2\% D-mannose was added (Vagarali MA et al., 2008).

\section{Serotyping}

Few randomly selected isolates of E. coli having one or more virulence markers were subjected for serotyping. Monovalent E. coli antisera belonging to serogroups $01,06,08$, 015, 018, 020, 025 (Denka Seikien, Tokyo, Japan) were used. E.coli isolates were looked for strong agglutination with antisera within 1 minute (according to manufacturer's instructions).

\section{Antibiotic Susceptibility Testing}

Antibiotic Susceptibility Testing were done on Mueller Hinton agar using Kirby- Bauer disc diffusion method.

\section{Results and Discussion}

\section{Virulence Markers}

In this study all the 210 E. coli isolates from cases of UTI were tested for the presence of following virulence markers namely; Hemolysin production, Mannose- resistant haemagglutination (MRHA) and Mannosesensitive haemagglutination (MSHA) and Cell surface hydrophobicity.

Out of the total 210 isolates tested, 117 isolates showed the presence of Virulence markers (Table 1). It is observed that Hemolytic activity was shown by 75 (35.71\%) isolates. Of those 210 isolates, 82 showed Haemagglutination (HA) of group O RBCs and 128 were non- hemolytic. Out of 82 isolates showing Heamagglutination, 59 (28\%) were MRHA positive and 23 (11\%) were MSHA. Hydrophobicity was shown by $61(29.04 \%)$ isolates. It was observed that 
among the different virulence markers tested Hemolysin production was most commonly found, followed by Cell surface hydrophobicity (Table 2).

Out of 117 isolates showing virulence markers, 29 (24.78\%) showed the presence of all the virulence markers tested. 43 (36.75\%) showed two virulence markers and $45(38.46 \%)$ showed one virulence marker. Of the one virulence marker positive isolates most commonly Haemagglutination was found in $30(66.7 \%)$ cases followed by Hemolysin $24.4 \%$ of cases. In two virulence marker positive isolates, most common combination was Hemolysin and cell surface hydrophobicity found in 20 (46.57\%) cases. Hemolysin and Haemagglutination was found to be next common combination present in 15 (34.97\%) isolates.

\section{Antibiotic Sensitivity}

Antibiotic sensitivity pattern (Table 3) of Uropathogenic E. coli showed maximum resistance to Ampicillin (79.05\%) followed by Nalidixic acid (77.15\%), Ciprofloxacin $(73.81 \%)$ and Cotrimoxazole $(63.81 \%)$. The high prevalence of resistance to these antibiotics is a matter of concern since all these antibiotics are commonly used for treatment of Urinary tract infection. Least resistance was seen with Nitrofurantion (14.29\%), followed by Gentamicin $(21.91 \%)$. When the antibiotic sensitivity pattern was observed in relation to the virulence markers it was seen that virulence marker positive strains were more sensitive to the antibiotics. As shown in Figure 1, Virulence marker positive strains were found to be most sensitive to Nitrofurantoin $86.32 \%$ (101/117) whereas 84.94\% (79/93) Virulence marker negative strains were sensitive to Nitrofurantoin. Same was the case with Gentamicin 82.90\% (97/117) sensitive in case of virulence marker positive strains in comparison to $72.04 \%$
(67/93) in virulence marker negative strains.

\section{Serotyping}

Out of 117 virulence marker positive E. coli isolates, 56 isolates could be serotyped and out of those, 41 were typable and 15 isolates were non- typable. Serotyping was done using the following available antisera $(\mathrm{O} 1$, O4, O6, O15, O18, O20 and O25). It was observed that most of the isolates $26.8 \%$ $(15 / 56)$ belonged to the serogroup O6, followed by $\mathrm{O} 8$ (23.2\%) (Table 4). Other serogroups less commonly found includes $\mathrm{O} 25, \mathrm{O} 18$ and $\mathrm{O} 20$ with $8.9 \%, 7.1 \%$ and $7.1 \%$ of isolates respectively. None of the isolates belonged to the serogroup $\mathrm{O} 1$ and O15.

Subject of Uropathogenic E. coli is receiving increased attention now a days because of the high degree of morbidity and mortality attached to UTIs. Uropathogenic E. coli produces several virulence markers which provide them with an increased advantage to colonize the urinary tract and cause disease. In this study significant percentage of UPEC showed the presence of virulence markers and these correlated well with studies done by other workers (Esparis CM et al., 2006; Fatima $\mathrm{N}$ et al., 2012; Orskov I et al., 1982; Ranjan KP et al., 2010). Thus, it is inferred that UPEC are definitely associated with aetio-pathogenesis of UTI. Hemolytic activity of $E$. coli is associated with Hemolysin production. Hemolysin contribute to tissue injury and survival in renal parenchyma and it has been suggested that colonization with hemolytic strains of $E$. coli is more likely to develop into urinary tract infections (Sharma $\mathrm{S}$ et al., 2007). Cytotoxicity and making iron available for the growth of bacterium appear to be the most likely mechanisms by which hemolysin may function to increase the virulence of UPEC (Fatima N et al., 2012). 
Table.1 Showing Total Virulence Marker Positive Isolates

\begin{tabular}{lcc}
\hline Virulence marker & Number of Isolates & Percentage \\
Virulence Marker Positive & 117 & 55.71 \\
Virulence Marker Negative & 93 & 44.29 \\
Total Cases & $\mathbf{2 1 0}$ & $\mathbf{1 0 0}$ \\
\hline
\end{tabular}

Table.2 Showing Various Virulence Markers in Total Number of Isolates

\begin{tabular}{lcc}
\hline Virulence markers & $\begin{array}{l}\text { No. of isolates of } \boldsymbol{E} . \\
\text { Coli giving positive } \\
\text { results }\end{array}$ & $\begin{array}{l}\text { Percentage of } \\
\text { the total (210 } \\
\text { isolates) }\end{array}$ \\
Hemolysin production & 75.00 & 35.71 \\
Mannose- resistant haemagglutination & 59.00 & 28.00 \\
Mannose- sensitive haemagglutination & 23.00 & 11.00 \\
Cell surface hydrophobicity & 61.00 & 29.04 \\
\hline
\end{tabular}

Table 3: Showing Antibiotic Sensitivity Pattern of the Isolated Escherichia coli

\begin{tabular}{lccc} 
Antibiotics & $\begin{array}{c}\text { Number of isolates } \\
\text { sensitive to the } \\
\text { antibiotic }\end{array}$ & Sensitive (\%) & $\begin{array}{c}\text { Resistant } \\
(\boldsymbol{\%})\end{array}$ \\
Ampicillin & 44.00 & 20.95 & 79.05 \\
Nalidixic acid & 48.00 & 22.85 & 77.15 \\
Nitrofurantoin & 180.0 & 85.71 & 14.29 \\
Ciprofloxacin & 55.00 & 26.19 & 73.81 \\
Cotrimoxazole & 76.00 & 36.19 & 63.81 \\
Gentamicin & 164.0 & 78.09 & 21.91 \\
Cefotaxime & 86.00 & 40.95 & 59.05 \\
Ceftazidime & 75.00 & 35.71 & 64.29 \\
\hline
\end{tabular}

Table.4 Showing Serogrouping of the few Selected Virulence Marker Positive E. Coli

\begin{tabular}{ccc} 
Serogroup & Number & Percentage \\
01 & 0 & 0.00 \\
06 & 15 & 26.8 \\
08 & 13 & 23.2 \\
015 & 0 & 0.00 \\
018 & 4 & 7.10 \\
020 & 4 & 7.10 \\
025 & 5 & 8.90 \\
NON-TYPABLE & 15 & 26.8 \\
\hline TOTAL & $\mathbf{5 6 ~ 1 0 0}$ &
\end{tabular}


Figure.1 Antibiotic Sensitivity Pattern of Isolated E. coli in Relation To Virulence Markers

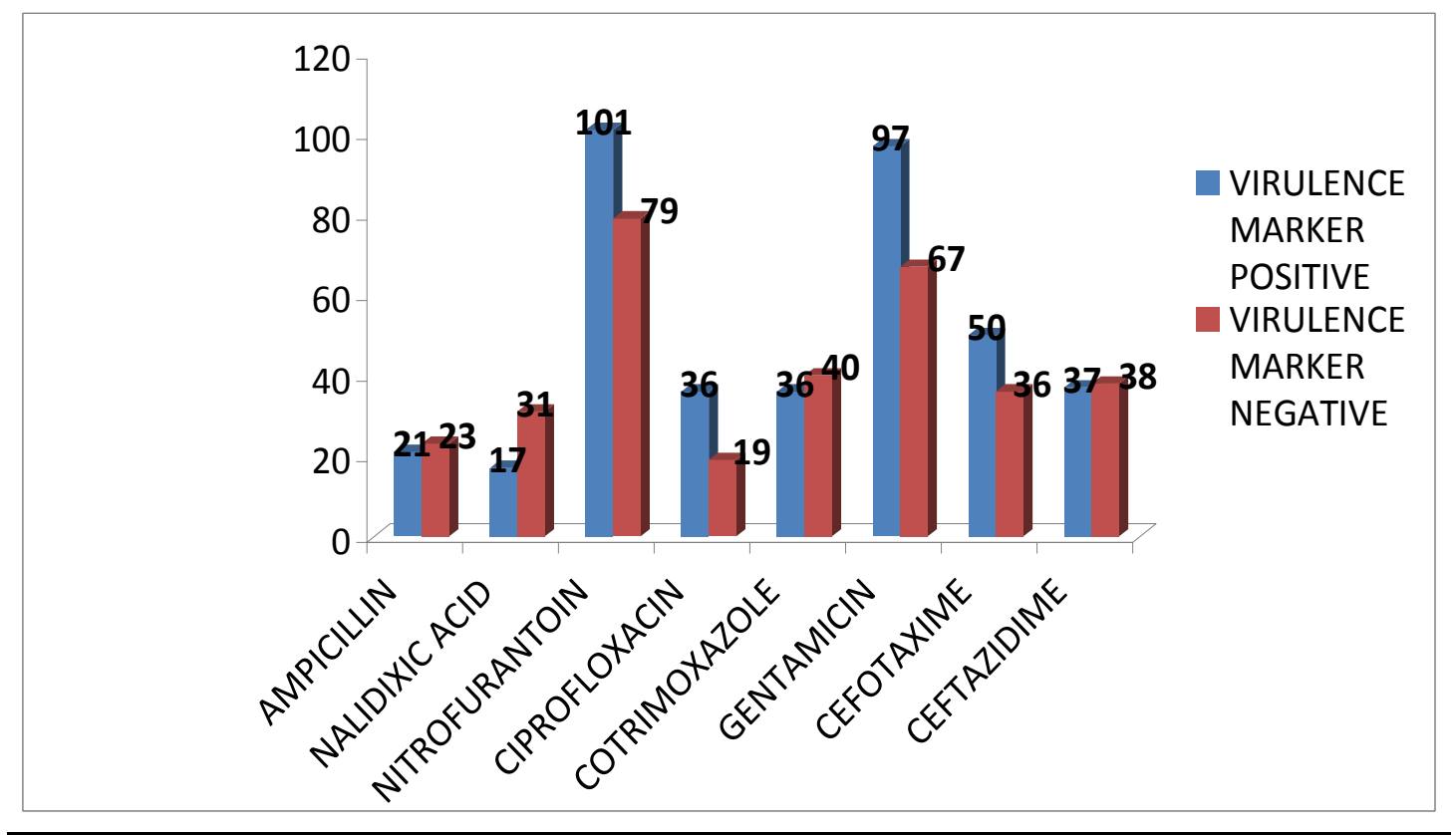

Figure.2 Culture of Urine via Standard Loop Method Showing Colonies of Escherichia coli

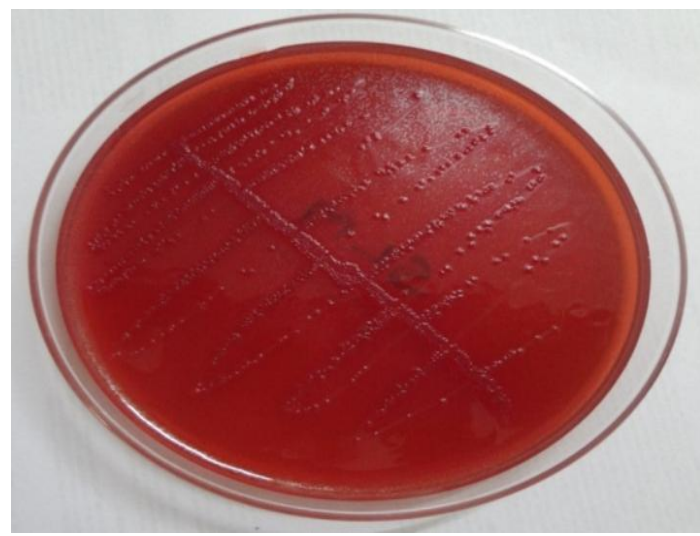

Figure.3 Hemolysin Production by E. coli (1 and 4 Isolate)

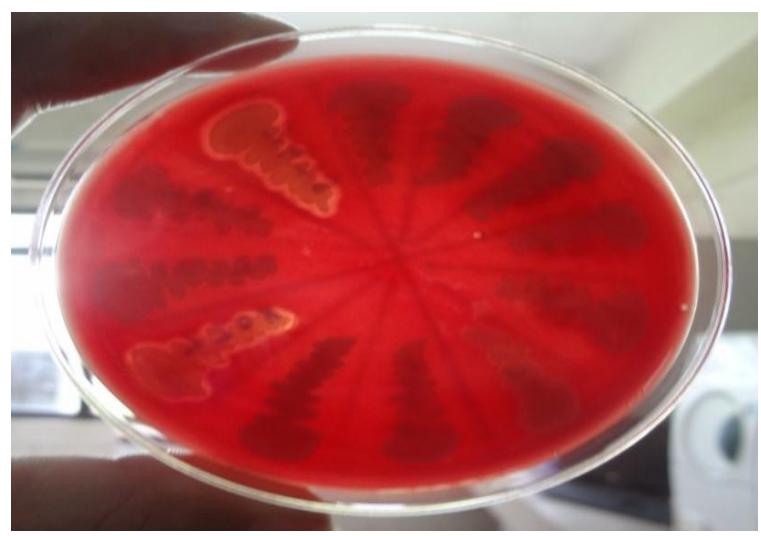


Figure.4 Haemagglutination Test

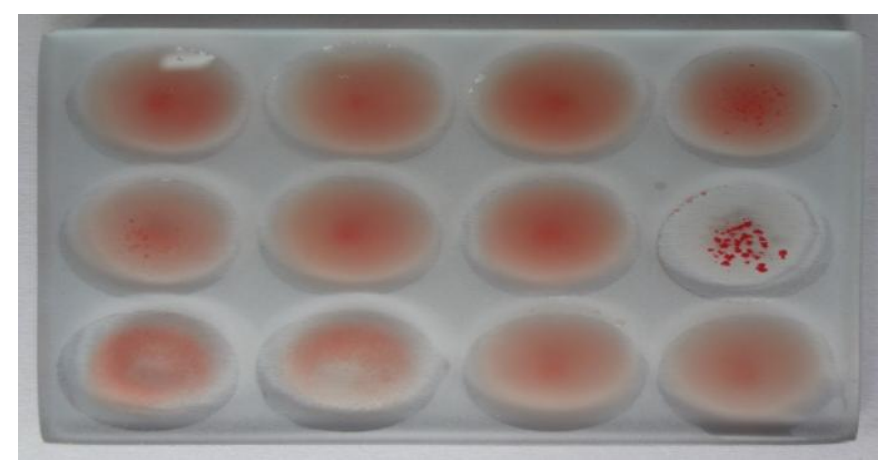

Mudd and Mudd first conceived the role of Cell Surface Hydrophobicity (CSH) in mediating bacterial adherence to mammalian cells (Mudd S, Mudd EB., 1924). Surface hydrophobicity is another important virulence factor of $E$. coli that causes extraintestinal infections. The high hydrophobicity of bacterial cell surface promotes their adherence to various surfaces like mucosal epithelial cells (Sharma $\mathrm{S}$ et al., 2007). In the present study significant number of Uropathogenic E. coli showed hydrophobicity, the figure correlates well with study done by Raksha $\mathrm{R}$ and coworkers (Raksha R et al., 2003).

Presence of fimbriae on E.coli can be indirectly established by the agglutination of human erythrocytes by that E.coli strain (Kallenius G et al., 1980; Steadman R, Topley N., 1998). MRHA positive strains can be considered as UPEC most likely having $\mathrm{P}$ fimbriae. E. coli strains causing severe forms of UTI are reported to exhibit Mannose resistant haemagglutination (Kallenius G et al., 1980). The expression of type 1 fimbriae is indicated by MSHA (Raksha $\mathrm{R}$ et al., 2003). In this study the percentage of UPEC showing MRHA and MSHA were similar to findings of other workers (Fatima N et al., 2012; Raksha R et al., 2003; Vagarali MA et al., 2008).

Uropathogenic E. coli belonging to certain serogroups possesses certain specific virulence factors which enhance their ability to cause infection. In most studies $E$. coli isolated from urinary tract infections belonged to 'uropathogenic' serotypes 01 , 02, 04, 06, 07, 08, 016, 018, 025 and 075 (Vosti KL et al., 1964). In this study most common serogroups was 06 followed by 08 . Several other workers also reported serotype 06 to be most frequently isolated from urine (Esparis CM et al., 2006; Orskov I et al., 1982).

UTIs are common infections and increased antimicrobial resistance hinder their treatment. The most commonly used antibacterial drugs in the treatment of UTI are Trimethoprim/ Sulfamethoxazole, Ciprofloxacin, Cephalosporins, semisynthetic Penicillins with or without inhibitors, Nitrofurantoin and Fosfomycin (Arslan $\mathrm{H}$ et al., 2005). In this study, high level of resistance were found among the Uropathogenic $E$. coli isolates for commonly used drugs like Ampicillin, Nalidixic acid, Cotrimoxazole. But when the antibiotic sensitivity pattern was observed in relation to Virulence markers (Figure: 1), it was found that the isolates showing virulence markers were more sensitive to drugs in comparison to virulence marker negative strains. These results support the hypothesis that although virulence factors and antibiotic resistance may confer increased fitness for extra-intestinal infections in humans, they may do so via mutually exclusive pathways 
and in distinct populations. A robust virulence factor repertoire may be essential for a pathogen to overcome intact host defenses, whereas it may be unnecessary in a compromised host, where antibiotic resistance may provide a substantial advantage to the survival of the pathogen (Sharma S et al., 2007).

In this study, it is concluded that uropathogenic $E$. coli are definitely associated with Urinary tract infection. Various virulence factors like, Hemolysin, Haemagglutination and cell surface hydrophobicity facilitate extraintestinal survival and enable UPEC to colonize the urinary tract and cause disease. It was also seen that the UPEC exhibited high level antibiotic resistance. It is possible that irrational prescribing of antimicrobials, available over the-counter (OTC) in India, has contributed to this high level of antibiotic resistance in Uropathogenic $E$. coli.

\section{Acknowledgment}

We would like to offer our sincere gratitude to the Department of Biotechnology, Govt. of India, New Delhi and DBT Nodal Centre, Tezpur, for selecting this study for MD/MS Thesis grant and providing with financial assistance for smooth conductance of the same.

\section{References}

Agarwal J, Srivastava S, Singh M. 2012. Pathogenomics of uropathogenic Escherichia coli. Indian J Med Microbiol. 30(2): 141-9.

Arslan H, Azap OK, Erqonul O, Timurkaynak F. 2005. Risk factors for ciprofloxacin resistance among Escherichia coli strains isolated from community acquired urinary tract infection in Turkey. $\mathrm{J}$ Antimicrob Chemother. 56(5):914-8.

Eden CS, Hanson LA, Jodal U, Lindberg U, Akerlund AS.1976. Variable adherence to normal human urinary-tract epithelial cells of Escherichia coli strains associated with various forms of urinary-tract infection. Lancet. 1 : 4902.

Esparis CM, Teixeira LM, Irino $\mathrm{K}$, et al. 2006. Biological and molecular characteristics of uropathogenic Escherichia coli strains isolated in the city of Rio de Janeiro. Rev Soc Bras Med Trop. 39(6); 573-6.

Fatima N, Mithlesh A, Shukla I, Khan PA. 2012. Characterization of Uropathogenic E. coli in relation to virulence factors. Open Access Scientific Reports. Available at http://www.omisconline.org/scientificreports/srep342.php. September 3rd 2013.

Forbes BA, Sahm DF, Weissfeld AS. 2007. Infections of the Urinary Tract. In: Bailey and Scott's. Diagnostic Microbiology. $12^{\text {th }}$ ed. Philadelphia: CV Mosby Company; 842-55.

Foxman B. 2003. Epidemiology of urinary tract infections: incidence, morbidity, and economic costs. Dis Mon. 49(2):53-70.

Johnson JR. 1991. Virulence factors in Escherichia coli urinary tract infection. Clinical Microbiology Rev. 4(1):80128.

Kallenius G, Mollby R, Winberg J. 1980. In vitro adhesion of uropathogenic Escherichia coli to human periurethral cells. Infect Immun. 28: 972-980.

Kaper JB, Nataro JP, Mobley HL. 2004. Pathogenic Escherichia coli. Nat Rev Microbiol. 2:123- 40.

Mudd S, Mudd EB. 1924. The penetration of bacteria through capillary spaces IV. A kinetic mechanism in interfaces. 40: 
633-645.

Nataro JP, Mobley HL. 2004. Pathogenic Escherichia coli. Nat Rev Microbiol. 2 : 123-40.

Orskov I, Orskov F, Birch-Andersen A, Kanamori M, Svanborq-Eden C. 1982. $\mathrm{O}, \mathrm{K}, \mathrm{H}$ and fimbrial antigens in Escherichia coli serotypes associated with pyelonephritis and cystitis. Scand J Infect Dis Suppl. 33: 18-25.

Raksha R, Srinivasa H, Macaden RS. 2003. Occurrence and characterization of uropathogenic Escherichia coli in urinary tract infections. Indian $\mathbf{J}$ Med Microbiol. 21(2):102-7.

Ranjan KP, Ranjan N, Chakraborty A, Arora DR. 2010. An approach to uropathogenic Escherichia coli in urinary tract infections. J Lab Physicians. 2(2):70-3.

Sandberg T, Kaijser B, Lidin-Janson G, Lincoln K, Orskov F, Orskov I, et al. 1988. Virulence of Escherichia coli in relation to host factors in women with symptomatic urinary tract infection. $\mathrm{J}$ Clin Microbiol. 26 : 1471-6.

Sharma S, Bhat GK, Shenoy S. 2007. Virulence factors and drug resistance in
E. coli isolated from Extra intestinal infections. Indian J Med Microbiol. 25 (4): 369-373.

Steadman R, Topley N. 1998. The virulence of Escherichia coli in urinary tract. In: Brumfitt W, Jeremy MT, Hamilton M, editors. Urinary tract infections. $1^{\text {st }}$ ed. London: Chapman and Hall; 37-41.

Vagarali MA, Karadesai SG, Patil CS, Metgud SC, Mutnal MB. 2008. Haemagglutination and siderophore production as the urovirulence markers of uropathogenic E. coli. Indian J Med Microbiol. 26(1): 68-70.

Vosti KL, Goldberg LN, Monto AS, Rantz LA. 1964. Host parasite interaction in patients with infections due to Escherichia coli I. The serogrouping of E. coli from intestinal and extraintestinal sources. J Clin Invest. 43: 2377-2378.

Wullt B. 2003. The role of P fimbriae for Escherichia coli establishment and mucosal inflammation in the human urinary tract. Int $\mathbf{J}$ Antimicrob Agents. 21(6) : 605-21.

\section{How to cite this article:}

Tarulata Saikia, Jayanta Kr. Das, Dipa Barkataky and Hazarika, N. K. 2016. Detection of Virulence Markers in Uropathogenic Escherichia coli, their Serotypes and Antibiotic Sensitivity Patterns. Int.J.Curr.Microbiol.App.Sci.5(4): 784-792.

doi: http://dx.doi.org/10.20546/ijcmas.2016.504.090 